Arq. Bras. Med. Vet. Zootec., v.61, supl. 1, p.77-84, 2009

\title{
Situação epidemiológica da brucelose bovina no Estado do Rio de Janeiro
}

[Epidemiological situation of bovine brucellosis in the State of Rio de Janeiro, Brazil]

\author{
M.F.C. Klein-Gunnewiek ${ }^{1}$, M. Amaku ${ }^{1}$, R.A. Dias ${ }^{1}$, F. Ferreira ${ }^{1}$, C.B. Gitti ${ }^{2}$, L.A. Pereira ${ }^{3}$, \\ V.C.F. Figueiredo ${ }^{4}$, J.R. Lobo ${ }^{4}$, V.S.P. Gonçalves ${ }^{5}$, J.S. Ferreira Neto ${ }^{1 *}$ \\ ${ }^{1}$ Faculdade de Medicina Veterinária e Zootecnia - USP \\ Av. Prof. Dr. Orlando Marques de Paiva, 87 \\ 05508-270 - São Paulo, SP \\ ${ }^{2}$ Faculdade de Medicina Veterinária e Zootecnia - UFRRJ - Seropédica, RJ \\ ${ }^{3}$ Secretaria de Estado de Agricultura, Abastecimento, Pesca e Desenvolvimento do Interior - Niterói, RJ \\ ${ }^{4}$ Departamento de Saúde Animal - SDA-MAPA - Brasília, DF \\ ${ }^{5}$ Faculdade de Agronomia e Medicina Veterinária - UnB - Brasília, DF
}

\begin{abstract}
RESUMO
Realizou-se um estudo para caracterizar a situação epidemiológica da brucelose bovina no Estado do Rio de Janeiro. O Estado foi dividido em três circuitos produtores. Em cada circuito foram amostradas aleatoriamente cerca de 300 propriedades e, dentro dessas, foi escolhido, de forma aleatória, um número pré-estabelecido de animais, dos quais foi obtida uma amostra de sangue. No total foram amostrados 8239 animais, provenientes de 945 propriedades. Em cada propriedade amostrada foi aplicado um questionário epidemiológico para verificar o tipo de exploração e as práticas zootécnicas e sanitárias que poderiam estar associadas ao risco de infecção pela doença. O protocolo de testes utilizado foi o da triagem com o teste do antígeno acidificado tamponado e reteste dos positivos com o teste do 2-mercaptoetanol. O rebanho foi considerado positivo se pelo menos um animal foi reagente às duas provas sorológicas. Para o Estado, as prevalências de focos e de animais infectados foram, respectivamente, de 15,4\% [12,9-17,9\%] e de $4,1 \%$ [2,8-5,3\%]. Para os circuitos, as prevalências de focos e de animais infectados foram, respectivamente: circuito $1,13,8 \%[10,2-18,2 \%]$ e $3,0 \%$ [1,9-4,1\%]; circuito $2,15,7 \%$ [11,9-20,2\%] e $2,3 \%$ [1,4-3,2\%]; circuito $3,19,6 \%[15,4-24,4 \%]$ e $9,3 \%$ [4,5-14,1\%]. Os fatores de risco (odds ratio, OR) associados à condição de foco foram: ter mais que 30 fêmeas com idade de 24 meses ou acima $(\mathrm{OR}=2,33[1,51-3,07])$, compra de reprodutores $(\mathrm{OR}=1,95[1,13-2,45])$ e prática de aluguel de pasto $(\mathrm{OR}=1,74[1,03-2,74])$.
\end{abstract}

Palavras-chave: bovino, brucelose, prevalência, fatores de risco, Rio de Janeiro

\begin{abstract}
A study to characterize the epidemiological status of bovine brucellosis in the State of Rio de Janeiro was carried out. The State was divided in three regions. Three hundred herds were randomly sampled in each region and a pre-established number of animals were sampled in each herd. A total of 8,239 serum samples from 945 herds were collected. In each herd, it was applied an epidemiological questionnaire focused on herd traits as well as husbandry and sanitary practices that could be associated with the risk of infection. The serum samples were screened for antibodies against Brucella spp. by the Rose-Bengal Test (RBT), and all positive sera were re-tested by the 2-mercaptoethanol test (2-ME). The herd was considered positive if at least one animal was positive on both RBT and 2-ME tests. The prevalences of infected herds and animals in the State were, respectively: $15.4 \%$ [12.9-17.9\%] and 4.1\% [2.8-5.3\%]. The prevalences of infected herds and animals in the regions were, respectively: region 1, 13.8\% [10.2$18.2 \%]$ and 3.0\% [1.9-4.1\%]; region 2, 15.7\% [11.9-20.2\%] and 2.3\% [1.4-3.2\%]; and region 3,
\end{abstract}

Recebido em 27 de março de 2009

Aceito em 23 de setembro de 2009

* Autor para correspondência (corresponding author)

E-mail: jsoares@vps.fmvz.usp.br 


\section{Klein-Gunnewiek et al.}

19.6\% [15.4-24.4\%] and 9.3\% [4.5-14.1\%]. The risk factors (odds ratio, OR) associated with the presence of the infection were: herd size larger than 30 cows $(O R=2.33$ [1.51-3.07]), purchase of animals for breeding $(O R=1.95$ [1.13-2.45), and pasture rental practice $(R=1.74$ [1.03-2.74]).

Keywords: cattle, brucellosis, prevalence, risk factors, Rio de Janeiro, Brazil

\section{INTRODUÇÃO}

A introdução de bovinos no Brasil remete aos tempos do Brasil colônia. Em 1534, Tomé de Sousa e, em 1550, Dona Ana Pimentel, esposa de Martim Afonso de Souza, trouxeram de Cabo Verde para a Bahia e para a Capitania de São Vicente, respectivamente, gado comum não especializado de origem ibérica para ser utilizado nas feitorias e engenhos (Silva, 1947). No Estado do Rio de Janeiro, relatos indicam que por volta do início do século XVII, na região hoje chamada Baixada Fluminense, já havia um rebanho de aproximadamente onze mil cabeças de gado na Fazenda Santa Cruz (Domingues, 1982). Somente no fim do século 19, porém, teve início a importação de raças européias para o Rio de Janeiro, Rio Grande do Sul e São Paulo e zebuínos para a Bahia, Rio de Janeiro e Minas Gerais (Jardim, 1983). A primeira importação de gado Zebu foi realizada na última metade do século XIX, por fazendeiros de Cantagalo, RJ, que mandaram vir do zoológico de Londres, exemplares de gado indiano (Domingues, 1966). A intenção era produzir bois de carro para utilização nas fazendas de café. Dessa forma, coube ao Estado do Rio ser a primeira região do Brasil a receber e disseminar bovinos com este propósito (Domingues, 1966). Entretanto, um dos fatores que limitou a expansão dos rebanhos no próprio Estado foi a falta de campos naturais, sendo impossível o aumento do efetivo bovino sem o sacrifício de áreas de lavoura de café e cana-de-açúcar que, na época, ocupavam a maior parte das terras do Estado e representavam atividades lucrativas (Silva, 1947). Mesmo com rebanhos de menor porte, era no Estado do Rio que os criadores dos demais Estados vinham comprar reprodutores para o melhoramento genético de seus plantéis.

Situado na região Sudeste do Brasil, o Estado do Rio de Janeiro é um dos menores Estados da Federação, ocupando uma área total de $43.766,6 \mathrm{~km}^{2}$ (Rio de Janeiro, 2007). O efetivo bovino atual é de 2.003.852 cabeças (IBGE, 2006). Atualmente, a agropecuária tem pouca expressão na produção econômica do Estado, representando em torno de $0,4 \%$ do produto interno bruto e contribuindo com apenas $5 \%$ da produção de leite da região Sudeste do Brasil (IBGE, 2006).

Em 1975, foi realizado o primeiro inquérito sorológico nacional para brucelose bovina, e no Estado do Rio de Janeiro a frequência de animais soropositivos foi de 4,6\% (Brasil, 1977). O teste utilizado foi $\mathrm{o}$ da soroaglutinação rápida em placa. Desde então, nenhum novo estudo sorológico estadual para brucelose bovina de caráter oficial foi registrado.

No período de fevereiro a agosto de 2000 , foram examinadas para diagnóstico de brucelose 1.229 amostras de soros bovinos provenientes de 135 propriedades distribuídas em 59 municípios do Estado do Rio de Janeiro. Foi observada a frequência de $42,3 \%$ de propriedades-foco e $6,2 \%$ de animais positivos. A prova utilizada foi a do antígeno acidificado tamponado (Folhadella et al., 2001). O Rio de Janeiro nunca desenvolveu um programa próprio de combate à brucelose bovina e a situação epidemiológica da doença no Estado não é adequadamente conhecida.

O presente estudo, portanto, teve por objetivos estimar a prevalência e identificar os fatores de risco para a brucelose bovina no Estado, e fornecer informações epidemiológicas para a melhor implementação e gestão do Programa Nacional de Controle e Erradicação de Brucelose e Tuberculose (PNCEBT).

\section{MATERIAL E MÉTODOS}

O estudo foi planejado por técnicos do Ministério da Agricultura, Pecuária e Abastecimento, da Universidade de São Paulo e da Universidade de Brasília, em colaboração com técnicos da Secretaria de Agricultura, Abastecimento, Pesca e Desenvolvimento do Interior (SEAAPI), RJ. O trabalho de campo foi realizado por técnicos da SEAAPI/RJ, no período de fevereiro de 2003 a junho de 2004. 
Para que fossem conhecidas as diferenças regionais nos parâmetros epidemiológicos da brucelose bovina, o Estado do Rio foi dividido em três circuitos produtores de bovinos, levandose em consideração os diferentes sistemas de produção, práticas de manejo, finalidades de exploração, tamanho médio de rebanhos e sistemas de comercialização. A divisão do Estado em regiões correspondentes a circuitos produtores também levou em conta a capacidade operacional e logística do serviço veterinário oficial do Estado para a realização das atividades de campo, baseando-se nas áreas de atuação das suas unidades regionais.

Em cada circuito produtor, estimou-se a prevalência de propriedades infectadas pela brucelose bovina e a de animais soropositivos por meio de um estudo amostral em dois estágios, dirigido para detectar focos da doença. No primeiro estágio, sorteou-se, aleatoriamente, um número pré-estabelecido de propriedades com atividade reprodutiva (unidades primárias de amostragem). No segundo, sorteou-se um número pré-estabelecido de fêmeas bovinas com idade igual ou superior a 24 meses (unidades secundárias de amostragem).

Nas propriedades rurais onde existia mais de um rebanho, foi escolhido o rebanho bovino de maior importância econômica, no qual os animais estavam submetidos ao mesmo manejo, ou seja, sob os mesmos fatores de risco. A escolha da unidade primária de amostragem foi aleatória, baseada no cadastro de propriedades rurais com atividade reprodutiva de bovinos. A propriedade sorteada que, por motivos vários, não pôde ser visitada, foi substituída por outra, nas proximidades e com as mesmas características de produção. $\mathrm{O}$ número de propriedades selecionadas por circuito foi estimado pela fórmula para amostras simples aleatórias (Thrusfield, 2007). Os parâmetros adotados para o cálculo foram: nível de confiança de 0,95 , prevalência estimada de 0,25 e erro de 0,05. A capacidade operacional e financeira do serviço veterinário oficial do Estado também foi levada em consideração para a determinação do tamanho da amostra por circuito.

O planejamento amostral para as unidades secundárias visou estimar um número mínimo de animais a serem examinados dentro de cada propriedade de forma a permitir a sua classificação como foco ou não foco de brucelose. Para tanto, foi utilizado o conceito de sensibilidade e especificidade agregadas (Dohoo et al., 2003). Para efeito dos cálculos foram adotados os valores de $95 \%$ e $99,5 \%$, respectivamente, para a sensibilidade e a especificidade do protocolo de testes utilizado (Fletcher et al., 1998) e 20\% para a prevalência estimada. Nesse processo foi utilizado o programa Herdacc versão 3, e o tamanho da amostra escolhido foi aquele que permitiu valores de sensibilidade e especificidade de rebanho iguais ou superiores a $90 \%$. Assim, nas propriedades com até 99 fêmeas com idade superior a 24 meses, foram amostrados 10 animais e nas com 100 ou mais fêmeas com idade superior a 24 meses, 15 animais. A escolha das fêmeas dentro das propriedades foi casual sistemática.

O protocolo do sorodiagnóstico foi composto pela triagem com o teste do antígeno acidificado tamponado (Rosa Bengala), seguida do reteste dos positivos com o teste do 2-mercaptoetanol, de acordo com as recomendações do PNCEBT (Brasil, 2006). O sangue foi coletado por punção da veia jugular com agulha descartável estéril em tubo com vácuo, previamente identificado. Os soros, armazenados em microtubos de plástico, foram mantidos a $-20^{\circ} \mathrm{C}$ até a realização dos testes. Os testes sorológicos foram realizados na Empresa de Pesquisa Agropecuária do Estado do Rio de Janeiro (PESAGRO).

A propriedade foi considerada positiva quando se detectou pelo menos um animal positivo. As propriedades que apresentaram animais com resultado sorológico inconclusivo, sem nenhum positivo, foram classificadas como suspeitas e excluídas das análises. O mesmo tratamento foi dado aos animais com resultados sorológicos inconclusivos.

O planejamento amostral permitiu determinar as prevalências de focos e de fêmeas adultas ( $\geq 24 \mathrm{~m}$ ) soropositivas para brucelose no Estado e também nos circuitos produtores. Os cálculos das prevalências aparentes e os respectivos intervalos de confiança foram realizados conforme preconizado por Dean et al. (1994). Os cálculos das prevalências de focos e de animais no Estado, e de prevalências de animais dentro das 
regiões foram feitos de forma ponderada (Dohoo et al., 2003).

O peso de cada propriedade no cálculo da prevalência de focos no Estado foi dado por

$$
P_{1}=\frac{\text { propriedades na região }}{\text { propriedades amostradasna região }}
$$

O peso de cada animal no cálculo da prevalência de animais no Estado foi dado por

$$
P_{2}=\frac{\text { fêmeas } \geq 24 \text { meses na propriedade }}{\text { fêmeas } \geq 24 \text { meses amostradas na propriedade }} \times \frac{\text { fêmeas } \geq 24 \text { meses na região }}{\text { fêmeas } \geq 24 \text { meses nas propriedades amostradas na região }}
$$

$\mathrm{Na}$ expressão acima, o primeiro termo refere-se ao peso de cada animal no cálculo das prevalências de animais dentro das regiões.

Em cada propriedade amostrada, além da coleta de sangue para a sorologia, foi também aplicado um questionário epidemiológico, elaborado para obter informações sobre o tipo de exploração e as práticas de manejo empregadas.

As variáveis analisadas foram: tipo ou sistema de exploração (carne, leite e misto), tipo de criação (confinado, semiconfinado, extensivo), uso de inseminação artificial, raças predominantes, número de vacas com idade superior a 24 meses, número de bovinos na propriedade, presença de outras espécies domésticas, presença de animais silvestres, destino da placenta e dos fetos abortados, compra e venda de animais, vacinação contra brucelose, abate de animais na propriedade, aluguel de pastos, pastos comuns com outras propriedades, pastos alagados, piquete de parição e assistência veterinária.

Quando necessário, realizou-se a recategorização das variáveis. A categoria de menor risco foi considerada como base para a comparação das demais categorias. As variáveis quantitativas foram categorizadas em percentis.

Foi feita uma primeira análise exploratória dos dados (univariada) para seleção daquelas com $\mathrm{p} \leq 0,20$ para o teste do $\chi^{2}$ ou exato de Fisher e, subsequente, oferecimento dessas à regressão logística. Os cálculos foram realizados com o auxílio do programa SPSS, versão 9.0.

Todas as informações geradas pelo trabalho de campo e de laboratório foram inseridas em um banco de dados específico, utilizado nas análises epidemiológicas.

\section{RESULTADOS E DISCUSSÃO}

O Estado foi dividido em três diferentes circuitos produtores (Fig. 1). Os dados censitários tomados como base para os cálculos da amostra e das prevalências foram os mais atualizados disponíveis à época do trabalho de campo em 2001. A Tab. 1 traz um resumo desses dados censitários e também da amostra estudada em cada um dos circuitos produtores.

$\mathrm{Na}$ Tab. 2, apresentam-se os resultados de prevalência de focos no Estado e nos circuitos produtores. Na Tab. 3, mostra-se a prevalência por tipo de exploração da propriedade e na Tab. 4 , a prevalência de animais.

Na Tab. 5, mostram-se os resultados da análise univariada e na Tab. 6, o modelo final da regressão logística.

A prevalência de focos de brucelose no Estado foi de 15,4\% (Tab. 2). Entre os circuitos, embora os valores absolutos mostrem maior prevalência de focos no circuito 3 e menor no 1 , não há diferença estatisticamente significativa entre eles (Tab. 2). Na Tab. 3, mostra-se que nos três circuitos a prevalência de focos nas propriedades do tipo corte, leite e misto também não diferem. Segundo Pereira (2007; SEAAPI, Niterói-RJ; comunicação pessoal), o circuito 1 detém aproximadamente a metade dos bovinos do Estado (Tab. 1), onde predomina propriedades do tipo corte, com animais criados de forma extensiva. Nos circuitos 2 e 3 predominam propriedades de leite e mistas (Pereira, 2007; SEAAPI, Niterói-RJ; comunicação pessoal).

A prevalência de animais soropositivos para brucelose foi de $4,1 \%$ (Tab. 4), praticamente a mesma encontrada no estudo do Ministério da Agricultura em 1975 (4,6\%) (Brasil, 1977) e não muito diferente da verificada por Folhadella et al. (2000) em dezembro de 1997 (6,2\%). É importante lembrar que a metodologia utilizada nesses dois estudos foi diferente da empregada no presente trabalho. 


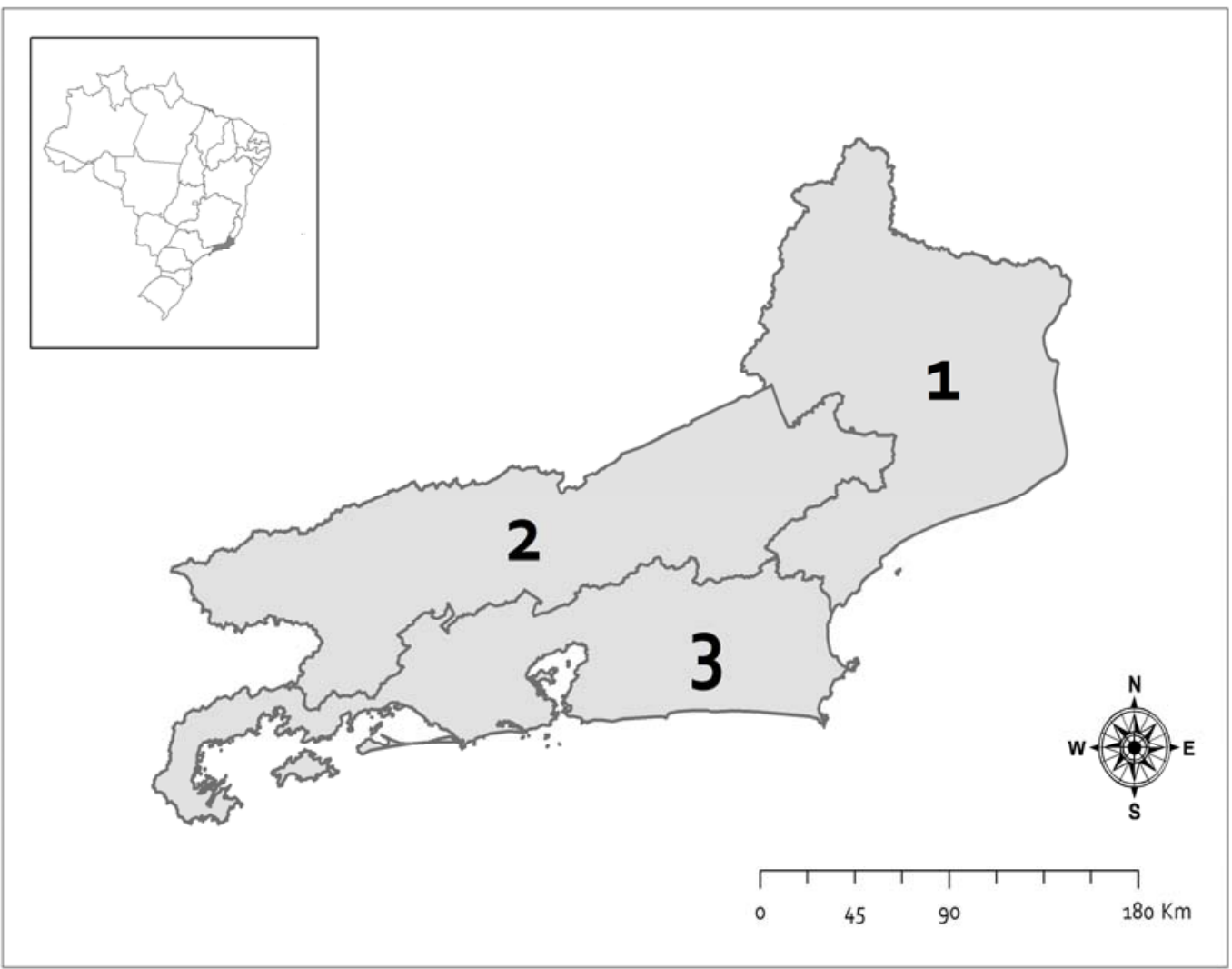

Figura 1. Mapa do Estado do Rio de Janeiro com a divisão em circuitos produtores. No detalhe, a localização do Estado do Rio de janeiro no Brasil.

Tabela 1. Dados censitários da população bovina do Estado do Rio de Janeiro em 2001, segundo o circuito produtor

\begin{tabular}{|c|c|c|c|c|c|}
\hline $\begin{array}{l}\text { Circuito } \\
\text { produtor }\end{array}$ & $\begin{array}{l}\text { Núcleo de defesa sanitária } \\
\text { animal }\end{array}$ & $\begin{array}{l}\text { Total de } \\
\text { propriedades } \\
\text { com atividade } \\
\text { reprodutiva }\end{array}$ & $\begin{array}{c}\text { Propriedades } \\
\text { amostradas }\end{array}$ & $\begin{array}{l}\text { Total de } \\
\text { fêmeas } \\
\text { com idade } \\
\geq 24 \text { meses }\end{array}$ & $\begin{array}{l}\text { Fêmeas } \\
\text { amostradas }\end{array}$ \\
\hline 1- Norte & $\begin{array}{l}\text { Campos dos Goytacazes, } \\
\text { Macaé, São Francisco de } \\
\text { Itabapoana, Itaperuna, } \\
\text { Itaocara, Santo Antônio de } \\
\text { Pádua, Natividade, Bom } \\
\text { Jesus do Itabapoana }\end{array}$ & 18.566 & 311 & 514.731 & 2.708 \\
\hline 2- Centro-Oeste & $\begin{array}{l}\text { Cordeiro, Nova Friburgo, } \\
\text { Santa Maria Madalena, } \\
\text { Resende, Barra Mansa, Piraí, } \\
\text { Vassouras, Três Rios, Barra } \\
\text { do Piraí }\end{array}$ & 9.181 & 318 & 232.761 & 2.863 \\
\hline 3- Sul-Litoral & $\begin{array}{l}\text { Casimiro de Abreu, Niterói, } \\
\text { Cachoeira de Macacu, Rio } \\
\text { Bonito, Araruama, Angra } \\
\text { dos Reis e Rio de Janeiro }\end{array}$ & 6.377 & 316 & 184.043 & 2.668 \\
\hline Total & & 34.124 & 945 & 931.535 & 8.239 \\
\hline
\end{tabular}




\section{Klein-Gunnewiek et al.}

Tabela 2. Prevalência de focos de brucelose bovina na propriedade, segundo circuito produtor, no Estado do Rio de Janeiro

\begin{tabular}{lcccc}
\hline \multirow{2}{*}{ Circuito produtor } & \multicolumn{2}{c}{ Propriedades } & \multirow{2}{*}{ Prevalência (\%) } & IC (95\%) \\
\cline { 2 - 3 } & Testadas & Positivas & & \\
\hline 1- Norte & 311 & 43 & 13,85 & {$[10,19-18,17]$} \\
2- Centro-Oeste & 318 & 50 & 15,72 & {$[11,90-20,19]$} \\
3- Sul-Litoral & 316 & 62 & 19,62 & {$[15,38-24,43]$} \\
Total & 945 & 155 & 15,42 & {$[12,91-17,91]$} \\
\hline
\end{tabular}

IC: intervalo de confiança.

Tabela 3. Prevalência (Prev) de focos de brucelose bovina estratificada por tipo de exploração, segundo o circuito produtor, no Estado do Rio de Janeiro

\begin{tabular}{|c|c|c|c|c|c|c|}
\hline \multirow{2}{*}{$\begin{array}{l}\text { Circuito } \\
\text { produtor }\end{array}$} & \multicolumn{2}{|r|}{ Corte } & \multicolumn{2}{|c|}{ Leite } & \multicolumn{2}{|c|}{ Misto } \\
\hline & Prev (\%) & IC $(95 \%)$ & Prev (\%) & IC $(95 \%)$ & Prev (\%) & IC (95\%) \\
\hline 1- Norte & 9,75 & {$[2,72-23,13]$} & 15,18 & {$[9,98-21,75]$} & 13,39 & {$[7,6-21,12]$} \\
\hline 2- Centro-Oeste & 6,25 & {$[0,76-20,80]$} & 14,52 & {$[9,71-20,55]$} & 20,56 & {$[13,35-29,45]$} \\
\hline 3-Sul-Litoral & 22,2 & {$[11,20-37,08]$} & 22,95 & {$[15,82-31,43]$} & 16,10 & {$[10,60-23,01]$} \\
\hline
\end{tabular}

IC: intervalo de confiança.

Tabela 4. Prevalência de bovinos sororreagentes para brucelose, segundo o circuito produtor, no Estado do Rio de Janeiro

\begin{tabular}{lcccc}
\hline \multirow{2}{*}{ Circuito produtor } & \multicolumn{2}{c}{ Animais } & \multirow{2}{*}{ Prevalência (\%) } & \multirow{2}{*}{ IC (95\%) } \\
\cline { 2 - 3 } & Testados & Positivos & & \\
\hline 1- Norte & 2.708 & 67 & 3,01 & {$[1,93-4,09]$} \\
2- Centro-Oeste & 2.863 & 69 & 2,32 & {$[1,41-3,23]$} \\
3- Sul-Litoral & 2.668 & 112 & 9,30 & {$[4,52-14,08]$} \\
Total & 8.239 & 248 & 4,08 & {$[2,83-5,33]$} \\
\hline
\end{tabular}

IC: intervalo de confiança.

Tabela 5. Resultados da análise univariada dos possíveis fatores de risco para brucelose bovina em rebanhos com atividade reprodutiva no Estado do Rio de Janeiro

\begin{tabular}{lccc}
\hline Variável & Expostos/casos & Expostos/controles & $\mathrm{p}$ \\
\hline Sistema de criação extensivo & $102 / 155$ & $580 / 790$ & 0,053 \\
Exploração de corte & $16 / 155$ & $102 / 790$ & 0,373 \\
Ter mais de 30 fêmeas com 24 meses ou acima & $106 / 155$ & $316 / 790$ & $<0,001$ \\
Contato com ovinos e caprinos & $23 / 155$ & $78 / 790$ & 0,067 \\
Contato com equinos & $126 / 155$ & $600 / 790$ & 0,150 \\
Contato com suínos & $47 / 155$ & $239 / 790$ & 0,986 \\
Contato com aves & $85 / 155$ & $419 / 790$ & 0,681 \\
Contato com cão & $103 / 155$ & $516 / 790$ & 0,786 \\
Contato com gato & $54 / 155$ & $315 / 790$ & 0,240 \\
Contato com animais silvestres & $1 / 155$ & $10 / 790$ & $1,000^{*}$ \\
Contato com cervídeos & $6 / 155$ & $31 / 790$ & 0,975 \\
Contato com capybaras & $15 / 155$ & $81 / 790$ & 0,828 \\
Contato com outros animais silvestres & $18 / 155$ & $125 / 790$ & 0,181 \\
Utilizar a inseminação artificial & $23 / 155$ & $95 / 790$ & 0,333 \\
Comprar animais para reprodução & $89 / 155$ & $296 / 790$ & $<0,001$ \\
Ter histórico de aborto & $36 / 141$ & $138 / 763$ & 0,039 \\
Deixar produtos do aborto na pastagem & $95 / 155$ & $507 / 789$ & 0,482 \\
Abater animais na propriedade & $2 / 155$ & $21 / 790$ & $0,405^{*}$ \\
Alugar pasto & $26 / 155$ & $82 / 790$ & 0,022 \\
Ter pasto em comum com outras propriedades & $25 / 155$ & $115 / 790$ & 0,614 \\
Presença de áreas alagadiças & $53 / 155$ & $246 / 790$ & 0,455 \\
Presença de piquetes de parição & $78 / 155$ & $320 / 790$ & 0,024 \\
Não vacinar contra brucelose & $98 / 155$ & $577 / 788$ & 0,012 \\
\hline *T
\end{tabular}

${ }^{*}$ Teste exato de Fisher. 
Tabela 6. Modelo final da regressão logística múltipla de fatores de risco (odds ratio) para brucelose bovina em rebanhos com atividade reprodutiva no Estado do Rio de Janeiro, 2001

\begin{tabular}{lccc}
\multicolumn{1}{c}{ Variável } & Odds ratio & IC (95\%) & $p$ \\
\hline Ter mais de 30 fêmeas com 24 meses ou acima & 2,33 & {$[1,62-3,32]$} & $<0,001$ \\
Comprar animais para reprodução & 1,95 & {$[1,36-2,79]$} & $<0,001$ \\
Alugar pasto & 1,74 & {$[1,06-2,85]$} & 0,027 \\
\hline IC:
\end{tabular}

IC: intervalo de confiança.

No estudo publicado em 2000 (Folhadella et al., 2000), os autores utilizaram os testes de soroaglutinação rápida em placa com o antígeno acidificado tamponado e com o antígeno de Huddleson e os resultados de prevalência foram, respectivamente, $6,2 \%$ e $5,6 \%$. O objetivo foi determinar a prevalência de $B$. abortus em bovinos do Estado do Rio de Janeiro, porém não foi detalhado o planejamento amostral.

Esses resultados mostram que a prevalência da brucelose nos bovinos do Estado do Rio de Janeiro tem-se mantido elevada desde meados dos anos 1970 e, portanto, o Estado deverá fazer um esforço para a obtenção, em todos os anos, de uma cobertura vacinal mínima de $80 \%$ de fêmeas entre três e oito meses de idade com a vacina B19.

O modelo final da regressão logística indicou as variáveis compra de reprodutores, prática de aluguel de pasto e ter mais de 30 fêmeas com 24 meses de idade ou mais como fatores de risco para a brucelose (Tab. 6).

A compra de animais infectados é amplamente reportada como o principal fator de introdução de brucelose em rebanhos livres (Van Wavern, 1960; Nicoletti, 1980; Salman e Meyer, 1984). Em relação a essa variável, alguns fatores podem atuar de forma independente ou em associação, como: frequência de compra, origem dos animais e histórico de realização de testes sorológicos para brucelose (Crawford et al., 1990). Kellar et al. (1976) verificaram que propriedades-foco adquiriam animais de reposição com maior frequência do que propriedades livres. $\mathrm{Na}$ Escócia, Sarget et al. (1973) reportaram que os rebanhos apresentaram taxa significativamente maior de infecção por Brucella spp. quando a reposição do gado não era feita com animais da própria propriedade. $\mathrm{O}$ verdadeiro problema não é a introdução de animais, prática rotineira nos rebanhos bovinos, mas sim a aquisição de animais sem cuidados sanitários, ou seja, sem a realização de testes ou com desprezo da condição sanitária do rebanho de origem.

A prática de aluguel de pasto pode favorecer o contato dos animais com ambientes previamente contaminados. Dependendo das condições ambientais, os produtos do aborto poderão manter a Brucella spp. viável por até aproximadamente 180 dias (Crawford et al., 1990). Segundo Hipólito et al. (1965) e Wray (1975), o principal risco de infecção por Brucella abortus está relacionado à contaminação ambiental por produtos de aborto. Essa variável indica que o contato indireto entre propriedades está associado à condição de foco de brucelose no Estado.

Quanto ao tamanho do rebanho, verificou-se que as propriedades com mais de 30 vacas com idade igual ou superior a 24 meses tiveram 1,33 vezes mais chances de serem focos de brucelose do que aquelas com menor número de fêmeas (Tab. 6). Isso significa que a brucelose é mais frequente nas propriedades maiores, provavelmente porque introduzem reprodutores de outras propriedades com mais frequência. Entretanto, a intervenção sobre essa variável é destituída de senso prático. Assim, o Estado do Rio de Janeiro deverá dar especial atenção a duas práticas: desestimular a aquisição de reprodutores sem cuidados sanitários e evitar o contato indireto entre propriedades.

Os dados obtidos neste estudo deverão orientar o Serviço Oficial do Estado na planificação e racionalização do combate à brucelose. Além disso, permitirá avaliar periodicamente a eficácia das medidas adotadas.

Recomenda-se: concentrar esforços na obtenção, em todos os anos, de uma cobertura vacinal mínima de $80 \%$ de fêmeas entre três e oito meses de idade com a vacina B19; desencorajar a introdução de animais sem controle sanitário e 


\section{Klein-Gunnewiek et al.}

qualquer modalidade de contato direto entre propriedades.

\section{AGRADECIMENTOS}

À FAPESP, ao CNPq, à SEAAPI-RJ e ao MAPA pelo apoio financeiro.

\section{REFERÊNCIAS BIBLIOGRÁFICAS}

BRASIL. Ministério da Agricultura e Abastecimento. Diagnóstico de saúde animal. Brasília, 1977. 735p.

BRASIL. Ministério de Agricultura, Pecuária e Abastecimento. Programa Nacional de Controle e Erradicação da Brucelose e da Tuberculose Animal (PNCEBT): Manual técnico. Brasília, 2006. 184p.

CRAWFORD, R.P.; HUBER, J.D.; ADAMS, B.S. Epidemiology and surveillance. In: NIELSEN, K.; DUNCAN, J.R. (Ed.). Animal brucellosis. Boca Raton: CRC Press, 1990. p.131-151.

DEAN, A.G.; DEAN, J.A.; COLOMBIER, D. et al. Epi-Info, version 6: A word processing database and statistics program for epidemiology on microcomputers. Atlanta: CDC, 1994. 601p.

DOHOO, I.; MARTIN, W.; STRYHN, H. Veterinary epidemiologic research. Charlottetown, Canadá: Atlantic Veterinary College, 2003. 706p.

DOMINGUES, O. O gado indiano no Brasil. Rio de Janeiro: PLANAM, SUNAB, 1966. 422p.

DOMINGUES, O. O gado leiteiro para o Brasil: Gado europeu, gado indiano, gado bubalino. 9.ed. São Paulo: Nobel, 1982. 112p.

FLETCHER, R.H.; FLETCHER, S.W.; WAGNER, E.H. Clinical epidemiology: The essentials. 2.ed. Baltimore: Williams \& Wilkins, 1998. 246p.

FOLHADELLA, I.M.; JESUS, V.L.T.; FOLHADELLA, D.S. et al. Fatores de risco da ocorrência da brucelose bovina em rebanhos no Estado do Rio de Janeiro. Rev. Bras. Reprod. Anim., v.25, p.239-240, 2001.

FOLHADELLA, I.M.; SANTOS, A.G.; JESUS, V.L.T. et al. Soroaglutinação rápida em placa com antígeno de Hudleson e com antígeno acidificado na determinação da prevalência da brucelose bovina no Estado do Rio de Janeiro. In: JORNADA DE INICIAÇÃO CIENTÍFICA DA UFRRJ, 10., Rio de Janeiro, 2000. Seropédica: UFRRJ, 2000. p.233-234.

HIPÓlitO, O.; FREITAS, M.G.; FIGUEIREDO, J.B. Doenças infectocontagiosas dos animais domésticos. São Paulo: Melhoramentos, 1965. 596p.

IBGE. Censo agropecuário 2006: Resultados preliminares. Rio de Janeiro, 2006. Disponível em:

$<$ http://www.ibge.gov.br/home/estatistica/econo mia/agropecuaria/censoagro/2006/agropecuario.p df $>$. Acessado em: 11 jun. 2007.

JARDIM, W.R. Curso de bovinocultura. 5.ed. Campinas: Instituto Campineiro de Ensino Agrícola, 1983. 501p.

KELLAR, J.; MARRA, R.; MARTIN, W. Brucellosis in Ontario: a case control study. Can. J. Comp. Med., v.40, p.119-128, 1976.

NICOLETTI, P. The epidemiology of bovine brucellosis. Adv. Vet. Sci. Comp. Med., v.24, p.69-98, 1980.

RIO DE JANEIRO. Centro de Informações e Dados do Rio de Janeiro. Disponível em: $<$ http://www.cide.rj.gov.br/territorio_extensao.ph p>. Acessado em: 11 out. 2007.

SALMAN, M.D.; MEYER, M.E. Epidemiology of bovine brucellosis in the Mexicali Valley, México: literature review of disease-associated factors. Am. J. Vet. Res., v.45, p.1557-1560, 1984.

SARGET, E.D.; WILSON, A.L.; MUNRO, R.F. Brucellosis, an investigation on dairy farms in the west of Scotland. Auchincruive: The West of Scotland Agriculture College, 1973. (Report, n. 141).

SILVA, A.B. O zebu na Índia e no Brasil. Rio de Janeiro: 1947. 280p.

THRUSFIELD, M. Veterinary epidemiology. 3.ed. Oxford: Blackwell Science, 2007. 610p.

VAN WAVERN, G.M. The control of brucellosis in the Netherlands. Vet. Rec., v.72, p.928. 1960.

WRAY, C. Survival and spread of pathogenic bacteria of veterinary importance within the environment. Vet. Bull., v.8, p.543-550, 1975. 